\title{
BCLC Stage B Adult Hepatocellular
}

\section{Carcinoma}

National Cancer Institute

\section{Source}

National Cancer Institute. BCLC Stage B Adult Hepatocellular Carcinoma. NCI Thesaurus.

Code C115141.

Intermediate hepatocellular carcinoma. Patients may benefit from chemoembolization.

(HPB (Oxford) 2005; 7(1):35-41) 